\section{Poverty reduction must not exacerbate climate change}

SIR - Current international policy responses to the world's two most serious problems, poverty and climate change, seem to be pulling in opposite directions.

To boost economic growth in less developed countries, international development agencies and the World Trade Organization at the Doha conference in 2001 called for a reduction in European Union and US food subsidies and the removal of trade barriers. This drive towards globalization, resulting in a free flow of trade across borders, should benefit the poorest nations through increased access to global export markets, investment capital and improved technology. These in turn should increase job opportunities and reduce poverty. According to the World Bank's 2003 report, international tourism is expected to play a major role in sustainable development of all the 49 least developed countries, where it currently provides the primary source of foreign exchange earnings.

At the same time, the pressing need to reduce greenhouse-gas emissions is becoming ever clearer. Politicians can no longer evade a range of tough policy choices, as outlined in your Editorial "Light at the end of the tunnel" (Nature 445, 567; 2007).

International scientific and political debates on mitigating climate change through reducing emissions have begun to focus on the transport sector. This accounts for some $20 \%$ of global $\mathrm{CO}_{2}$ emissions, a share that is rising rapidly. In response, political pressure by environmental groups and concerned consumers is pushing retailers to reduce 'food miles' - the distance that products travel from field to plate - by sourcing food locally. Tourism is also being targeted by environmental campaigners, as a major contributor to climate change through aircraft emissions. International aviation and shipping are currently excluded from the national emission-control targets set under the Kyoto Protocol. However, it seems increasingly unlikely that such an exclusion from future agreements will be tenable, in the face of strong evidence for the seriousness of potential climate change.

A major disjunction is, therefore, looming between climate policy and strategies for reducing poverty. This illustrates the scale of the tough choices now facing politicians. Attempts to control greenhouse-gas emissions may restrict international trade and tourism, removing the key strategies for less developed countries to grow their way out of poverty. Ironically, the same countries are most vulnerable to the direct impacts of climate change and have the lowest capacity to adapt.

Climate change therefore seems to demand that the international community should find new ways of transferring wealth from rich to poor countries, instead of relying on everincreasing volumes of trade and tourism with their associated greenhouse-gas emissions. Terence P. Dawson, Simon J. Allen

Centre for the Study of Environmental Change and Sustainability, University of Edinburgh, West Mains Road, Edinburgh EH9 3JN, Scotland, UK

\section{Genetic test may lead to waste of healthy embryos}

SIR - Your News Feature "The first cut" (Nature 445, 479-480; 2007) highlights a controversy about preimplantation genetic diagnosis (PGD), a procedure to test for genetic disease that is now more widely used for screening chromosomes in embryos after in vitro fertilization (IVF). Randomized clinical trials are needed to determine whether aneuploidy screening improves pregnancy rates, or whether embryo biopsy has any impact on the health of future children and adults. There is less doubt, however, that PGD encourages the waste of healthy embryos. Your News Feature pointed out that this can potentially happen if mosaic embryos normalize in culture, but a significant fraction may occur from misdiagnosis.

Chromosomes are identified by spots of colour from fluorescent in situ hybridization (FISH), which has $90-92 \%$ accuracy, by some estimates. Is this good enough? At present, about half the karyotype is usually screened: nine autosomes plus two sex chromosomes. But, for every additional chromosome examined, the probability of a false result increases until, when all are screened, more than half of all embryos might be rejected, even if the accuracy is as high as $96 \%\left(0.96^{24}\right)$. If this prospect is not discouraging enough, then consider the FISH data themselves, even from the best screening centres.

During cell division, chromosome pairs normally segregate equally at opposite poles. When separation is premature or fails to happen, we expect to find an equal number of cells with an extra or a missing chromosome (monosomy), which is borne out by studies of human oocytes (see F. Pellestor et al. Hum. Genet. 112, 195-203; 2003). However, FISH data consistently show a significant bias and a two- to threefold excess of monosomy compared to trisomy. A higher error rate is anticipated for monosomy as hybridization can fail for many reasons, whereas an artefactual third signal is less likely. More perplexingly, however, the incidence of aneuploidy for each chromosome is so high that one wonders whether any embryo will be judged normal when the entire karyotype can be screened by this method.

Until a more reliable technology emerges, it is likely that many embryos will be needlessly discarded. This is perverse, as the goal is to improve pregnancy rates by selecting the best-quality embryos for transfer, particularly for older patients. The high incidence of aneuploidy in our species has encouraged this application of PGD, but best interests may not be served by liberal application and literal interpretation of current FISH technology. Sometimes a patient has no diploid embryos, causing her IVF cycle to be abandoned. Perhaps she should have any embryos with monosomy transferred, unless they are XO. At worst they will be nonviable, but at best they may produce a healthy child. Roger Gosden

Weill Medical College, Cornell University, New York, New York 10021, USA

\section{Intellectual edge can be gained in translation}

SIR — The Naturejobs Special Report "Lost in translation" (Nature 445, 454-455; 2007) discussed the importance of good English to a scientific career, as well as the difficulties experienced by scientists whose first language is not English. Having worked in four countries, and having a lab of eight people from seven different countries, I have found that languages are living entities that evolve continuously.

English is under the constant influence of other languages and cultures: 'latte', for example, now appears in the Oxford English Dictionary as well in cafés around the United Kingdom. Ironically, non-native speakers may communicate more easily in English with each other than with people whose only language is English. The key to communication is to learn languages: Latin, to start with, as it is a living component of scientific vocabulary. While we are at it, we may as well pronounce Latin as its native speakers did, not with an English accent. Any language will do, though, because speaking more than one is a great mental exercise. Relaxing into the comfort zone of one's native language, on the other hand, is a step towards mental lethargy.

We must all make an effort to read, write and speak good English in order to improve our communication in science. And I make no excuses for scientists who, like myself, come from countries where English is not the first language. At the same time, we should increase awareness of diversity. Cultural diversity, like genetic diversity, is one of our most precious assets. We must cherish, nurture and preserve both of them on a global scale. One way is to improve education, thus promoting tolerance. Francesco Colucci

The Babraham Institute, Babraham Research Campus, Cambridge CB22 3AT, UK

Readers are welcome to comment at http:// blogs.nature.com/nautilus/2007/02/

languages_of_science_1.html. 